\title{
Expanded HIV testing planned, but some remain less than positive
}

With the AIDS pandemic going strong and the prospects of a successful HIV vaccine uncertain, public health experts and advocacy groups are considering a new strategy that some claim could end the pandemic within 50 years.

The plan, which calls for universal annual testing followed immediately with antiretroviral therapy in infected individuals, could cut new HIV cases by an estimated $95 \%$ within a decade, according to a mathematical model used by the World Health Organization (WHO) (Lancet 373, 48-57; 2009). In November, human rights advocates and country representatives will meet at the WHO headquarters to map out a research agenda to test the model.

Similarly, in June the US National Institute of Allergy and Infectious Diseases (NIAID) announced plans for a pilot project this fall to see whether universal testing is feasible in the US (J. Am. Med. Assoc. 301, 2380-2382; 2009).

"No matter what we try, we can't seem to get below 56,000 new infections per year in the United States," NIAID Director Anthony Fauci told Nature Medicine. "So we're looking at bold new ways to prevent HIV, in addition to current strategies."

"I think the research agenda being proposed is critically important," says Ronald Johnson, deputy director of the AIDS Action Council, a US advocacy group. "But we have to see if it's a safe, efficient way to reach the goals of everyone knowing their status and linking everyone who is positive to care."

After peaking in the late 1990s, new HIV infections seem to have leveled off in the past decade. In 2007, 33 million people had the disease, but the WHO estimates that $80 \%$ of those infected don't know it. Countries use a suite of prevention tools, from education to voluntary testing to male circumcision, but only one in five people at risk has access to services, according to UNAIDS.

"If we want to get services, both treatment and prevention, to people living with HIV/ AIDS, we need to expand testing and have as many people as possible know their status," says Teguest Guerma, acting director of WHO's HIV/AIDS Department.

Scaling up testing globally, particularly in hard hit regions such as sub-Saharan Africa, can't be achieved without major changes in policy and social conditions, says Kevin Moody, chief executive author of GNP+, an Amsterdam-based advocacy group. "Given the inability of governments to live up to their commitments with respect to universal access for people living with HIV who meet requirements for treatment, it is difficult to imagine a situation where governments will be willing and able to address universal access for all who test HIV positive," he says.

Even at state or local levels, implementing universal testing has proved difficult. In 2006, the US Centers for Disease Control recommended opt-out, routine HIV testing for everyone ages 13 to 64 in all healthcare settings, even without written consent and prevention counseling. But studies show the guidelines aren't followed nationwide, in part because state laws prevent health officials from performing the tests without written consent and because health insurers are unwilling to pay for the tests (J. Am. Med. Assoc. 300, 945-951; 2008; Ann. Intern. Med. 150, 263-269; 2009).

In the meantime, cities and states are making changes. In Washington, DC, city council members are urging all medical providers there to implement a routine opt-out HIV testing policy. And a proposed bill in Florida would require insurers to cover routine HIV tests.

Alisa Opar, New York

\section{US moves on controversial travel ban}

For the first time in decades, HIV-positive individuals from other countries may soon be able to set foot on US soil. The nation's Department of Health and Human Services (HHS) is weighing comments on a proposal it released in early July to reverse the law that has prevented people with HIV from entering the US since 1987-a law that patient advocates

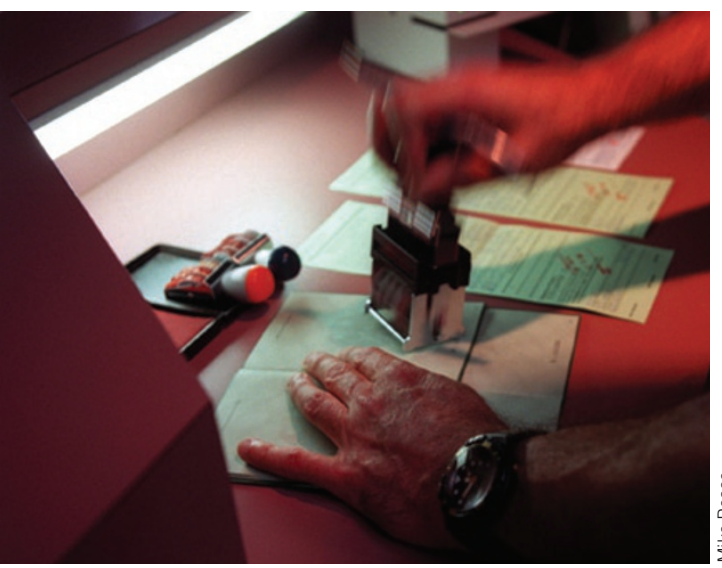

Stamp of approval: Rules nearly finalized have for years argued is counterproductive.

The US is one of only nine countries- the others include China, the United Arab Emirates and South Korea-that refuse admission to HIV-positive non-nationals for any reason (even just for airport layovers). The current ban flies in the face of a statement issued by the World Health Organization in 1988 that screening travelers for HIV is "ineffective, impractical and wasteful," argued the authors of a policy paper published by the International AIDS Society (IAS) in January 2009. The law, the IAS argued, may have encouraged people to lie on their immigration forms and leave antiretroviral drugs at home-and skipping doses increases the risk for drug resistance.

Former US President George W. Bush signed the pending reversal into law in 2008, but HHS must publish a final version of the changes before they go into effect. People with HIV will continue to be refused entry until the HHS finishes a 45-day public comment period on its proposal-it ends on August 17-and then publishes a final copy. The release of the proposal itself stirred some controversy: the initial copy was pulled and replaced two days later with a shortened version that, among other things, replaced the more burdensome 20-year projections regarding the costs and impacts of reversing the ban with five-year projections.

"Some language was rewritten to make the document more user friendly for a wider audience," explains Christine Pearson, a spokesperson for the US Centers for Disease Control and Prevention, the agency responsible for the documents. Pearson says that, given how rapidly HIV costs are changing, the "CDC felt it was more relevant to look at the impact five years out." She adds that it is "difficult to say" when the final version will be published and the ban lifted; it depends, in part, on how many comments the agency receives.

The IAS is certainly watching the progress closely the organization announced in June that it hopes to host its 2012 conference in Washington, DC. "We've made it clear in our advocacy that the International AIDS Conference cannot be held in any country that still holds these outdated discriminatory laws," says Ron MacInnis, the IAS's director of policy and programs.

Melinda Wenner, New York 